\title{
Granulocytic sarcoma of the breast: A case report
}

\author{
XIAO-E HUANG, YU-JIE LI and XIAO-DONG ZHOU \\ Department of Surgical Oncology, Yuyao People's Hospital of Zhejiang, Yuyao, Zhejiang 315400, P.R. China
}

Received August 29, 2014; Accepted June 23, 2015

DOI: $10.3892 / \mathrm{ol} .2015 .3532$

\begin{abstract}
Granulocytic sarcoma (GS) is an unusual type of tumor composed of immature cells outside the bone marrow. The disease exhibits a correlation with acute myeloid leukemia and other myeloproliferative disorders. Although it can invade a number of areas of the body, the involvement of the breast is uncommon. The present study reports the case of a 58-year-old female with a mildly tender lump in the left breast that had been apparent for one year. Available diagnostic techniques, including ultrasound, magnetic resonance imaging and mammography, were systematically used to determine a diagnosis of GS, and lumpectomy and systemic chemotherapy were performed. The patient was satisfied with the result of no local recurrence at the one year follow-up examination. The present study discusses the clinical and pathological characteristics of the present case of GC.
\end{abstract}

\section{Introduction}

The term granulocytic sarcoma (GS) designates an extramedullary manifestation of acute myeloid leukemia (AML). The tumors generally present with a green tint due to the presence of myeloperoxidase (MPO). GS occurs with an incidence of 2-14\% in AML (1). The bones, lymph nodes, soft tissues and skin are the most common sites of presentation of GS, with involvement of the breast being rare $(2,3)$.

A previous study reported patients without bone marrow infiltration may succumb to leukemia 16.5 months after the initial diagnosis (4). In order to eliminate diagnostic errors, mammography and magnetic resonance imaging (MRI) are commonly used. However, GS of the breast is often indistinguishable from benign tumors or lymphoma. For example, previous studies have reported patients presenting with an asymptomatic lump (5-8), while other studies have reported patients presenting with a tender lump (9-11). Therefore, it is difficult to define typical features of affected patients. In addition, diagnosis can only be confirmed through pathological examination with immuno-

Correspondence to: Miss. Xiao-E Huang, Department of Surgical Oncology, Yuyao People's Hospital of Zhejiang, 800 Chengdong Road, Yuyao, Zhejiang 315400, P.R. China

E-mail: liyujie24@gmail.com

Key words: granulocytic sarcoma, breast, case report histochemistry (12). Although a standard therapeutic approach for GS of the breast remains undefined, lumpectomy may be received as a good treatment strategy (13). The current study presents a case of GS of the breast and associated literature is reviewed. Written informed consent was obtained from the patient for inclusion in the present study.

\section{Case report}

A 58-year-old female presented to the Yuyao People's Hospital of Zhejiang (Yuyao, Zhejiang, China) on September 1, 2013, with an enlarged, painless and palpable mass in the left breast that had been present for one year. According to the French-American-British classification system (14), a primary diagnosis of AML-M6 had been made in another institution two years previously. Subsequently, the patient was treated with five cycles of an idarubicin and ara-C (cyarabine) regimen $\left(10 \mathrm{mg} / \mathrm{m}^{2}\right.$ idarubicin daily on days $1-3$ and $200 \mathrm{mg} / \mathrm{m}^{2}$ cytarabine daily on days 1-7) without improvement. Upon physical examination, a movable mass $4.0 \times 3.0 \mathrm{~cm}$ in diameter was palpated on the left breast, with no palpable axillary lymph nodes. The chest radiography was normal. Mammography showed a single, irregular, poorly-defined mass without calcification (Fig. 1A). The T2-weighted coronal images showed a single ill-defined inhomogeneous hyperintense mass compared with the breast parenchyma (Fig. 1B and C).

Gross examination revealed a relatively well-demarcated nodular lesion, which was green in color, measuring $4 \times 3 \mathrm{~cm}$ in width and covered by fibroadipose tissues (Fig. 2A). Histopathology revealed that the tumor was composed of small-sized cells with oval or round hyperchromatic nuclei and scant cytoplasm (Fig. 2B). Immunohistochemical analysis revealed that the tumor was positive for MPO and cluster of differentiation 68 (CD68), but negative for estrogen receptor, progesterone receptor, human epidermal growth factor receptor- 2 and p120 (Fig. 2C).

Postoperatively, the patient received three cycles of consolidation chemotherapy $\left(1 \mathrm{~g} / \mathrm{m}^{2}\right.$ cytarabine per $12 \mathrm{~h}$ on days $1-3$ and $12 \mathrm{mg} / \mathrm{m}^{2}$ idarubicin daily on days 1-2) and achieved complete remission. The patient also received ultrasound scans of the breast, chest X-ray and bone marrow aspiration every three months.

\section{Discussion}

GS usually occurs in multiple locations and exhibits rapid growth. GS in the breast is uncommon and may be 

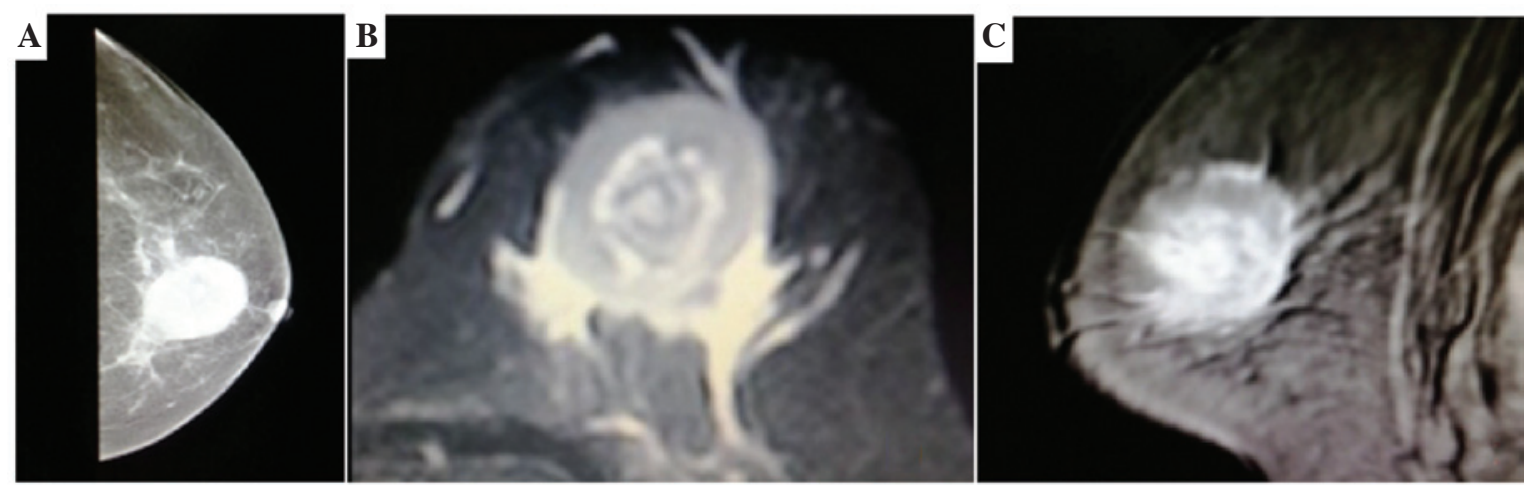

Figure 1. Mammography and T2-weighted coronal images. (A) Mammography showing a single, ill-defined, non-calcified mass in the left breast. (B and C) T2-weighted coronal images showing a single, ill-defined, inhomogeneous, hyperintense mass.
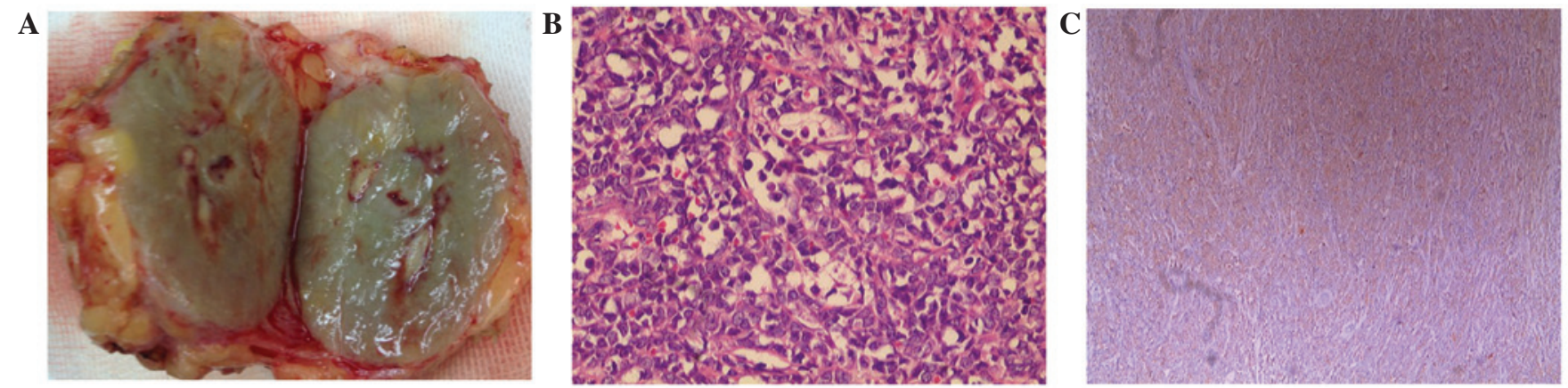

Figure 2. Gross examination and histopathology. (A) Gross appearance: Cut surface of the solid, green and well-demarcated tumor. (B) The cells are of small size with scanty cytoplasm, hyperchromatic nuclei and small nucleoli (hematoxylin and eosin stain; magnification, x200). (C) Myeloperoxidase reactivity is strongly positive in the tumor cells (immunohistochemistry with hematoxylin counterstain; magnification, $\mathrm{x} 40$ ).

misdiagnosed as lymphoma or carcinoma, particularly in the absence of invasion of the bone marrow. Viadana et al (15) reported only 4 cases (1.7\%) of breast involvement among 235 patients with AML.

Patients with GS of the breast mainly present with a painless mass and exhibit no other associated symptoms, such as nipple discharge or inversion (16). In the present case, the patient exhibited no evident symptoms, with the exception of a rapidly growing mass. Following MRI, T2-weighted coronal images showed the GS as a single ill-defined inhomogeneous hyperintense mass compared with the breast parenchyma. GS is difficult to distinguish from other types of tumor using mammography or breast ultrasonography (17).

D'Costa et al (18) identified small, hyperchromatic round- to oval-shaped cells exhibiting a high nuclear:cytoplasmic ratio, scant basophilic cytoplasm and coarse chromatin $(18,19)$, as was also observed in the present study. However, hematoxylin and eosin staining can reveal a range of changes in morphology, leading to the general misdiagnosis of GS as lymphoma or sarcoma (20). To confirm the final diagnosis of GS, the immunohistochemical detection of MPO-positive cells is useful. Mourad et al (21) and Pileri et al (22) reported that the expression levels of MPO-positive cells in GS were 66 and 83.6\%, respectively. Specific CD markers can also be useful. Mourad et al (21) compared 15 GS cases with non-Hodgkin's lymphoma (NHL) cases, and concluded that CD34 was positive in $46 \%$ of GS cases and negative in all NHL cases. By combining these observations with the history of AML, GS of the breast can be confirmed.

The therapeutic approaches for GS of the breast remain controversial. The majority of studies have concluded that all patients with GS should receive mastectomy or lumpectomy plus standard systemic chemotherapy $(3,4,23,24)$. Imrie et al (25) reported that the overall survival was longer in chemotherapy-treated patients compared with those who did not receive chemotherapy. The case presented in the current study was treated with lumpectomy and systemic chemotherapy, and no local recurrence was identified in the breast one year later.

In conclusion, it is difficult to make a clinical decision for the treatment of GS of the breast. The present study indicated that lumpectomy combined with systemic chemotherapy results in a good outcome for patients with GS of the breast. However, it is presumptuous to suggest that this is the most favorable treatment strategy for all patients. Further prospective, randomized, long-term follow-up investigations are required to validate our proposal.

\section{References}

1. Baer MR and Greer JP: Acute myeloid leukaemia in adults. In: Wintrobe's Clinical Haematology. Greer JP, Foerster J, Rodgers GM, et al. 12th Edition. Lippincott Williams \& Wilkins, Philadelphia, PA, pp1843-1888, 2009.

2. Quintas-Cardama A, Fraga M, Antunez J and Forteza J: Primary extramedullary myeloid tumor of the breast: A case report and review of the literature. Ann Hematol 82: 431-434, 2003. 
3. Barloon TJ, Young DC and Bass SH: Multicentric granulocytic sarcoma (chloroma) of the breast: Mammographic findings. AJR Am J Roentgenol 161: 963-964, 1993.

4. Paydas S, Zorludemir S and Ergin M: Granulocytic sarcoma: 32 cases and review of the literature. Leuk Lymphoma 47: 2527-2541, 2006.

5. Thachil J, Richards RM and Copeland G: Granulocytic sarcoma - a rare presentation of a breast lump. Ann R Coll Surg Engl 89: W7-W9, 2007.

6. Dutta Roy S, Stafford JS, Scally J and Selvachandran SN Granulocytic sarcoma of the breast antedating acute myelogenous leukemia. Breast 13: 242-246, 2004.

7. Barker TH: Granulocytic sarcoma of the breast diagnosed by fine needle aspiration (FNA) cytology. Cytopathology 9: 135-137, 1998

8. Ngu IW, Sinclair EC, Greenaway S and Greenberg ML: Unusual presentation of granulocytic sarcoma in the breast: A case report and review of the literature. Diagn Cytopathol 24: 53-57, 2001.

9. Stewart RL, Dell CM and Samayoa L: Myeloid sarcoma of the breast misdiagnosed as poorly differentiated mammary carcinoma with lobular features. Breast J 21: 192-193, 2015.

10. Gonçalves J, Louro LV, Ribeiro I, et al: Radiotherapy for granulocytic sarcoma of the breast-Case report and review of the literature. Rep Pract Oncol Radiother 19: 343-346, 2014.

11. Nishida H, Kinoshita T, Yashiro N, Ikeda Y and O'Uchi T: MR findings of granulocytic sarcoma of the breasts. Br J Radiol 79 : e112-e115, 2006

12. Fu J and Luo J: Granulocytic sarcoma of the breast in acute myeloid leukemia: Two case reports. Oncol Lett 7: 145-147, 2014.

13. Shea B, Reddy V, Abbitt P, Benda R, Douglas V and Wingard J: Granulocytic sarcoma (chloroma) of the breast: A diagnostic dilemma and review of the literature. Breast J 10: 48-53, 2004.

14. Bennett JM, Catovsky D, Daniel MT, Flandrin G, Galton DA, Gralnick HR and Sultan C: Proposals for the classification of acute leukemias. French-American-British (FAB) Cooperative Group. Br J Hematol 33: 451-458, 1976.

15. Viadana E, Bross ID and Pickren JW: An autopsy study of the metastatic patterns of human leukemias. Oncology 35: 87-96, 1978.
16. Valbuena JR, Admirand JH, Gualco G and Madeiros LJ: Myeloid sarcoma involving the breast. Arch Pathol Lab Med 129: 32-38, 2005.

17. Basara I and Orguc S: Giant breast involvement in acute lymphoblastic leukemia: MRI findings. J Breast Cancer 15: 258-260, 2012.

18. D'Costa GF, Hastak MS and Patil YV: Granulocytic sarcoma of breast: An aleukemic presentation. Indian J Med Sci 61: 152-155, 2007

19. Vela-Chávez TA, Arrecillas-Zamora MD, Quintero-Cuadra LY and Fend F: Granulocytic sarcoma of the breast without development of bone marrow involvement: A case report. Diagn Pathol 4: 2, 2009.

20. Nigam JS, Misra V, Kumar V and Varma K: Aleukemic granulocytic sarcoma presenting at multiple sites: Ovary, breast and soft tissue. Rare Tumors 4: e36, 2012.

21. Mourad W, Kfoury H and Al Husseini H: The value of CD34, myeloperoxidase and chloroacetate esterase (Leder) stain in the diagnosis of granulocytic sarcoma. Ann Saudi Med 21: 287-291, 2001.

22. Pileri SA, Ascani S, Cox MC, et al: Myeloid sarcoma: clinico-pathologic, phenotypic and cytogenetic analysis of 92 adult patients. Leukemia 21: 340-350, 2007.

23. Yamauchi K and Yasuda M: Comparison in treatments of nonleukemic granulocytic sarcoma: report of two cases and a review of 72 cases in the literature. Cancer 94: 1739-1746, 2002.

24. Tsimberidou AM, Kantarjian HM, Estey E, et al: Outcome in patients with nonleukemic granulocytic sarcoma treated with chemotherapy with or without radiotherapy. Leukemia 17: 1100-1103, 2003.

25. Imrie KR, Kovacs MJ, Selby D, Lipton J, Patterson BJ, Pantalony D, Poldre P, Ngan BY and Keating A: Isolated chloroma: The effect of early antileukemic therapy. Ann Intern Med 123: 351-353, 1995. 